\title{
Amendment effect of resveratrol on diclofenac idiosyncratic toxicity: Augmentation of the anti-inflammatory effect by assessment of Arachidonic acid and IL-1 $\beta$ levels
}

\author{
Omyma K. Radwan ${ }^{1}$, Rania F. Ahmed ${ }^{2 *}$ \\ ${ }^{1}$ Department of Physiology, National Organization for Drug Control and Research, Giza, Egypt. \\ ${ }^{2}$ Department of Pharmacology, National Research Centre, (ID: 60014618), Dokki, 12622, Giza, Egypt.
}

\section{ARTICLE INFO}

Article history:

Received on: 24/05/2016

Revised on: 08/06/2016

Accepted on: 10/07/2016

Available online: 28/12/2016

Key words:

Diclofenac, Resveratrol, interleukin-1 $\beta$, Arachidonic acid.

\begin{abstract}
Idiosyncratic drug induced liver injury (DILI) is one of the most serious hazards that could be induced due to the misuse of drugs. Diclofenac has long been well-known to prompt such complication. Resveratrol is one of the newest nutraceuticals that has been recently introduced in the medicinal field and proved to be effective in ameliorating many types of drug-induced hepatic injuries. The present study aimed to assess if combining resveratrol with diclofenac would result in hepato-protection and/or synergistic anti-inflammatory effect in an acute carrageenan induced paw edema model in rats. Results revealed that the combination groups showed augmented anti-inflammatory effect represented by decreased levels of interleukin-1 $\beta$ and arachidonic acid. Furthermore; combination groups diminished the inflammation-induced oxidative stress and nitrosative stress as shown in the reduction of GSSG/GSH ratio, MDA and $\mathrm{NO}_{\mathrm{X}}$ levels. Moreover; combination groups also prevented the elevation in liver enzymes namely AST and ALT. In conclusion we can say that addition of resveratrol to diclofenac tablets could be beneficial for patients suffering from serious liver conditions.
\end{abstract}

\section{INTRODUCTION}

Liver injury due to both prescription and over-thecounter drugs is a growing public health problem. Drug induced liver injury (DILI) is usually categorized into "intrinsic" and "idiosyncratic". Intrinsic hepatotoxic drug is characterized by dose-dependent hepatotoxicity. In contrast, idiosyncratic DILI is not clearly related to drug dose, route, or duration of administration. Despite the extensive safety tests performed in the process of getting a drug to market, DILI remains enigmatic and cannotf be predicted in preclinical and clinical trials (Iruzubieta et al., 2015). Redox cycling and generation of reactive oxygen and nitrogen species have been postulated to

\footnotetext{
* Corresponding Author

Rania F. Ahmed, Department of Pharmacology, National Research Centre, (ID: 60014618), Dokki, 12622, Giza, Egypt.

Email: dr_rania_fouad @ yahoo.com
}

explain cell damages including idiosyncratic toxicities of non-steroidal anti-inflammatory drugs (NSAIDs)(Droge, 2002, McMillian et al., 2004). Diclofenac is one of the most famous NSAIDs that is broadly prescribed for the treatment of a variety of rheumatoid disorders, including osteoarthritis, rheumatoid arthritis and acute muscle pain. Similar to other NSAIDs, diclofenac causes hepatic injury in patients. In fact, published cases of severe diclofenac hepatotoxicity amount to approximately 250 reports, with a case fatality rate of approximately $10 \%$, but the number of total serious hepatic adverse reactions (mostly unpublished) reported to the health authorities is several folds higher. Worse even, the real incidence has been estimated to be 10 - to 20 -fold higher than all reported cases, due to notorious underreporting (Boelsterli, 2003, Ramm and Mally, 2013). The cause of diclofenac-induced liver dysfunction in patients likely involves a response to oxidative stress and mitochondrial dysfunction in conjunction with metabolite binding (Boelsterli and Lim, 2007, Vickers et al., 2009). 
Resveratrol (3,5,4-trihydroxystilbene) is a polyphenolic compound that has been detected in fruits and some flowering plants. Resveratrol was reported to work as an anti-inflammatory (Timmers et al., 2012). Moreover; in vitro antioxidant properties were identified for resveratrol as it could provide protective antioxidant action in primary rat hepatocyte cultures (Rubiolo and Vega, 2008). Additionally, the protective role of resveratrol against a number of hepatic injuries was reported by several authors (Ahmed et al., 2014, Farghali et al., 2013, Powell et al., 2014).

The aim of the present study was to investigate if resveratrol would augment the anti-inflammatory effect of diclofenac and at the same time protect against its adverse hepatic side effects.

\section{MATERIAL AND METHODS}

\section{Animals}

Adult Female Wister rats, weighing 130-150 g each, purchased from the animal house at the National Research Centre (NRC, Giza, Egypt). All animals received human care in compliance with the guidelines of the EU Directive 2010/63/EU for animal experiments. Upon arrival, the animals were kept in a quiet place, housed eight per cage and acclimatized to a colony room with controlled ambient temperature $\left(22 \pm 1{ }^{\circ} \mathrm{C}\right)$, humidity $(50 \pm 10 \%)$ and a 12 hour natural light/dark cycle. They were fed a standard diet, water was provided ad libitum and they were acclimated for 7 days before entry into the subsequent study.

They were allowed free access to water and food throughout the period of investigation. The experiments were performed with 8 rats per treatment group according to a randomized schedule.

\section{Drugs and Drug Administration}

Diclofenac Sodium (Voltaren ${ }^{\circledR} ; 50 \mathrm{mg}$ sugar coated tablets, Novartis) and Diclofenac Potassium (Cataflam ${ }^{\circledR} ; 50 \mathrm{mg}$ sugar coated tablets, Novartis); the tablets were freshly suspended in distilled water prior to oral administration. Trans-resveratrol was provided as a generous gift from (Jing Tea LLC), it was provided as $250 \mathrm{mg}$ Harmoni-T micronized trans-resveratrol capsules for ingestion (trans-resveratrol in the capsules was extracted from the Asian plant Polygonum Cupsidatum). The powder in the capsules was freshly dissolved in distilled water just before oral administration.

\section{Experimental Design}

For the in vivo anti-inflammatory effect; rats were divided into groups (8 rats each) and were treated as follows; Group (1): Carrageenan group. Group (2): Resveratrol low (10 $\mathrm{mg} / \mathrm{kg}$ ) R10. Group (3): Resveratrol medium (20 mg/kg) R20. Group (4): Resveratrol high (40 mg/kg) R40. Group (5): Diclofenac sodium low (10 mg/kg) V10. Group (6): Diclofenac sodium medium (20 mg/kg) V20. Group (7): Diclofenac sodium high (40 mg/kg) V40. Group (8): Diclofenac potassium low (10 $\mathrm{mg} / \mathrm{kg}$ ) C10. Group (9): Diclofenac potassium medium (20 mg/kg) C20. Group (10): Diclofenac potassium high (40 mg/kg) C40. Group (11): Diclofenac sodium low + Resveratrol low $(10 \mathrm{mg} / \mathrm{kg}$ + $10 \mathrm{mg} / \mathrm{kg}$ ) RV10. Group (12): Diclofenac sodium medium + Resveratrol medium (20 mg/kg $+20 \mathrm{mg} / \mathrm{kg})$ RV20. Group (13): Diclofenac sodium high + Resveratrol high (40 mg/kg+ 40 mg/kg) RV40. Group (14): Diclofenac potassium low + Resveratrol low (10 mg/kg + $10 \mathrm{mg} / \mathrm{kg}$ ) RC10. Group (15): Diclofenac potassium medium + Resveratrol medium (20 mg/kg+ $20 \mathrm{mg} / \mathrm{kg}) \mathbf{R C 2 0}$. Group (16): Diclofenac potassium high +Resveratrol high (40 $\mathrm{mg} / \mathrm{kg}+40 \mathrm{mg} / \mathrm{kg}) \mathbf{R C 4 0}$.

\section{Experimental Procedure \\ Carrageenan- induced rat paw edema}

The method developed by (Winter et al., 1962) was employed. Animals were deprived of food for $12 \mathrm{~h}$ prior to experiment and only water was given ad libitum. First group (carrageenan group) received distilled water $(5 \mathrm{ml} / \mathrm{kg}$ p.o). Other groups received the corresponding drug treatments in distilled water orally. Concomitantly; carrageenan suspension $(0.1 \mathrm{ml}$ of $1 \% \mathrm{w} / \mathrm{v}$ suspension in $0.9 \%$ saline solution) was injected into the sub planter region of right hind paw of animals. Immediately before carrageenan injection, the paw volume was measured (initial paw volume) using plethysmometer (Harvard Apparatus Co. Model No.LE7500, USA).

Thereafter, the paw volume was measured after 1,2 and $3 \mathrm{~h}$ after carrageenan administration. The difference between initial $\left(\mathrm{V}_{\mathrm{b}}\right)$ and subsequent readings $\left(\mathrm{V}_{\mathrm{t}}\right)$ gave the change in edema volume for the corresponding time. \% Edema of control (Ec) and of treated $\left(\mathrm{E}_{\mathrm{t}}\right)$ were used to calculate percentage $(\%)$ inhibition and $(\%)$ edema volume by using following formula:

$$
\begin{aligned}
& \% \text { Edema }=\left[\left(\mathrm{V}_{\mathrm{t}}-\mathrm{V}_{\mathrm{b}}\right) / \mathrm{V}_{\mathrm{b}}\right] \times 100, \\
& \% \text { Inhibition }=\left[1-\left(\mathrm{E}_{\mathrm{t}} / \mathrm{E}_{\mathrm{C}}\right)\right] \times 100 .
\end{aligned}
$$

$\mathrm{V}_{\mathrm{t}}=$ edema volume after different time intervals, $\mathrm{V}_{\mathrm{b}}=$ basal edema volume, $(\mathrm{Ec})=\%$ Edema of control (carrageenan $),\left(\mathrm{E}_{\mathrm{t}}\right)=\%$ Edema of treated.

\section{Biochemical Analysis}

Immediately after the last measurement of paw edema rats were anesthetized using phenobarbital and the blood samples were collected and centrifuged. Serum was separated and used for further biochemical analyses. Blood samples were withdrawn from a group of eight normal animals to serve as normal control for the subsequent biochemical parameters

\section{Determination of serum arachidonic acid $(\mathrm{mg} / \mathrm{ml})$}

Arachidonic acid was determined by using GC method of (Ren et al., 2013). Arachidonic acid was purchased from SigmaAldrich and stored at $-35^{\circ} \mathrm{C}$ till used. The extraction of serum samples was prepared with Folch's solution, chloroform: methanol 
(2:1) then vortex for $2 \mathrm{~min}$ and centrifuged for $10 \mathrm{~min}$. at 4000 rpm. Standard and samples were allowed to evaporate at room temperature prior to extraction. Esterification was done by mixing the supernatant with $2 \mathrm{ml}$ of (95: 5 methanol: sulphuric acid) and heat in oven at $80{ }^{\circ} \mathrm{C}$ for $2 \mathrm{~h}$ and extracted with $2 \mathrm{ml}$ hexane.

Finally samples were ready for injection in the GC set loop. SupelcoSP2330 column, $30 \mathrm{~mm}$ X $0.32 \mathrm{~mm} \mathrm{X} 0.2 \mu \mathrm{m}$ film thickness, was used (Cat. No. 24073, Sigma-Aldrich, St. Louis, $\mathrm{MO})$.

Gas chromatography was done with an Agilent Technologies 7890A GC. Hydrogen was the carrier gas with a column head pressure of 10 psi. Total flow rate at the split vent was $50 \mathrm{ml} / \mathrm{min}$, the flow rate through the column was $2.5 \mathrm{ml} / \mathrm{min}$ and the septum purge was $2.5 \mathrm{ml} / \mathrm{min}$. The injector was set at $220^{\circ} \mathrm{C}$ using the splitless injection mode, and $1 \mu$ injections were made.

The temperature gradient started with a $70^{\circ} \mathrm{C}$ initial temperature, a linear increase to $170^{\circ} \mathrm{C}$ at $20^{\circ} \mathrm{C} / \mathrm{min}$, a slower linear increase to $170^{\circ} \mathrm{C}$ at $0.8^{\circ} \mathrm{C} / \mathrm{min}$ to separate closely-eluting fatty acids, followed by an increase to reach $220^{\circ} \mathrm{C}$ at $20^{\circ} \mathrm{C} / \mathrm{min}$, and a final $2.5 \mathrm{~min}$ hold. The total run time was 20.1 minutes. The detector was flame ionization detector FID.

\section{Determination of serum $I L-1 \beta(p g / m l)$}

IL-1 $\beta$ levels were determined by enzyme-linked immunosorbent assay (ELISA) kit(RayBio ® Rat IL-1 beta USA) according to (Sakamoto et al., 1994). The manufacturer's instructions (Invitrogen) were followed and finally the plate was read at $450 \mathrm{~nm}$ using ELISA reader.

\section{Determination of serum GSH (mmol/l) and GSSG (mmol/l) levels by $H P L C$}

Reduced glutathione (GSH) and oxidized glutathione (GSSG) levels were determined by HPLC using the method of (Jayatilleke and Shaw, 1993). The glutathione (GSH and GSSG) reference standards were purchased from Sigma Chemical Co. The samples were analyzed with the Agilent HP 1100 series HPLC apparatus (USA). The analytical column was a $\mu$-Bondapak column $(15 \mathrm{~cm} \times 3.9 \mathrm{~mm})$, UV detector and flow rate $1 \mathrm{ml} / \mathrm{min}$. The mobile phase consisted of $25 \mathrm{mmol}$ sodium dihydrogen phosphate containing $5 \mathrm{mmol}$ tetrabutylammonium phosphate and methanol.

\section{Determination of serum $\mathrm{NO}_{x}(\mu \mathrm{mol} / \mathrm{l})$ by $\mathrm{HPLC}$}

Total nitrite and nitrate accumulation was performed for indication of $\mathrm{NO}_{\mathrm{x}}$ production. The procedure for $\mathrm{NO}_{\mathrm{x}}$ determination was according to the HPLC method of (Papadoyannis et al., 1999), Sodium nitrite and sodium nitrate were used for the reference standard preparation with stock concentration $1 \mathrm{mg} / \mathrm{ml}$. The samples were analyzed with the
Agilent HP 1100 series HPLC apparatus (USA). The analytical column was an anion exchange PRP-X100 Hamilton, 150 X 4.1 $\mathrm{mm}$ by $10 \mathrm{~mm}$. The mobile phase was a mixture of $0.1 \mathrm{M}$ sodium chloride - methanol $(45: 55 \mathrm{v} / \mathrm{v})$, with a flow rate $2 \mathrm{ml} / \mathrm{min}$ and wavelength of $230 \mathrm{~nm}$, UV detector and flow rate $1 \mathrm{ml} / \mathrm{min}$.

\section{Determination of serum MDA (nmol/l) by HPLC}

Lipid peroxidation was assessed by determining the malondialdehyde (MDA) content by using HPLC according to the method of (Karatas et al., 2002). The MDA standard was prepared by dissolving $25 \mathrm{ml}$ 1,1,3,3 tetraethoxypropane (TEP) in $100 \mathrm{ml}$ of water to give a $1 \mathrm{mM}$ stock solution. The working standard was prepared by hydrolysis of $1 \mathrm{ml}$ TEP stock solution in $50 \mathrm{ml} 1 \%$ sulphuric acid and incubation for $2 \mathrm{~h}$ at room temperature.

The resulting MDA standard of $20 \mathrm{nmol} / \mathrm{ml}$ was further diluted with $1 \%$ sulphuric acid to yield the final concentration of $1.25 \mathrm{nmol} / \mathrm{ml}$, used as the standard for the estimation of total MDA.

The samples were analyzed with the Agilent HP 1200 series HPLC apparatus (USA). The analytical column was Supelcosil C18 (5 $\mu \mathrm{m}$ particle and 80 AO Pore size) (250X4.6 ID), UV detector and flow rate $1.2 \mathrm{ml} / \mathrm{min}$.

\section{Determination of serum ALT $(u / l)$ and AST $(u / l)$ levels}

Alanine aminotransferase (ALT) and aspartate aminotransferase (AST) activities were determined according to the method of (Reitman and Frankel, 1957) using colorimetric kits (SPECTRUM Egyptian company for biotechnology S.A.E). The manufacturer's instructions were followed and absorbances were measured at $505 \mathrm{~nm}$ using spectrophotometer to calculate the corresponding samples concentrations.

\section{Statistical Analysis}

Values were expressed as means \pm S.E. Comparisons between means were carried out using one way ANOVA followed by Tukey's multiple comparisons test. $\mathrm{P}<0.05$ was accepted as being significant in all types of statistical tests. Graph prism software (version 6) was used to carry out all statistical tests.

\section{RESULTS}

\section{Effect on carrageenan induced paw edema}

Carrageenan resulted in pronounced inflammation represented by exaggerated paw edema that increased from hour to hour. All treatments significantly prevented paw edema as compared to carrageenan group where combination groups showed comparable reduction in paw edema levels as compared to the corresponding standalone dose levels (Table1). 
Table 1: Effect of adding resveratrol to diclofenac on carrageenan induced paw edema in rats.

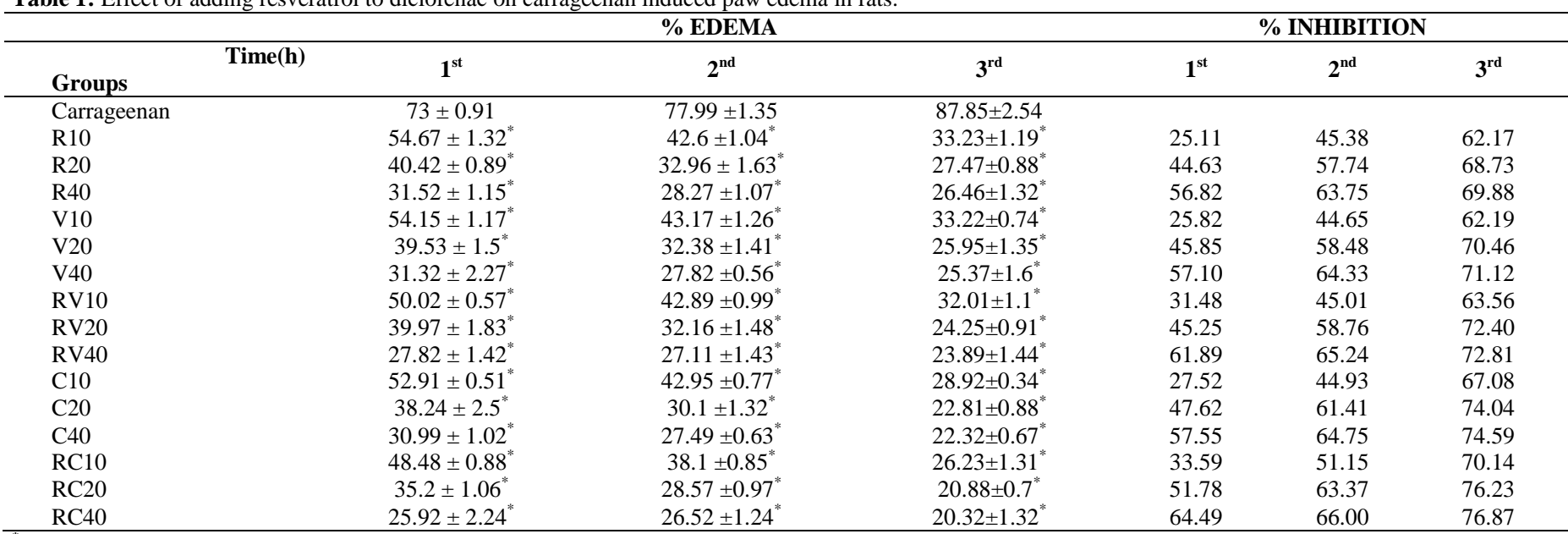

"Significantly different from Carrageenan group.

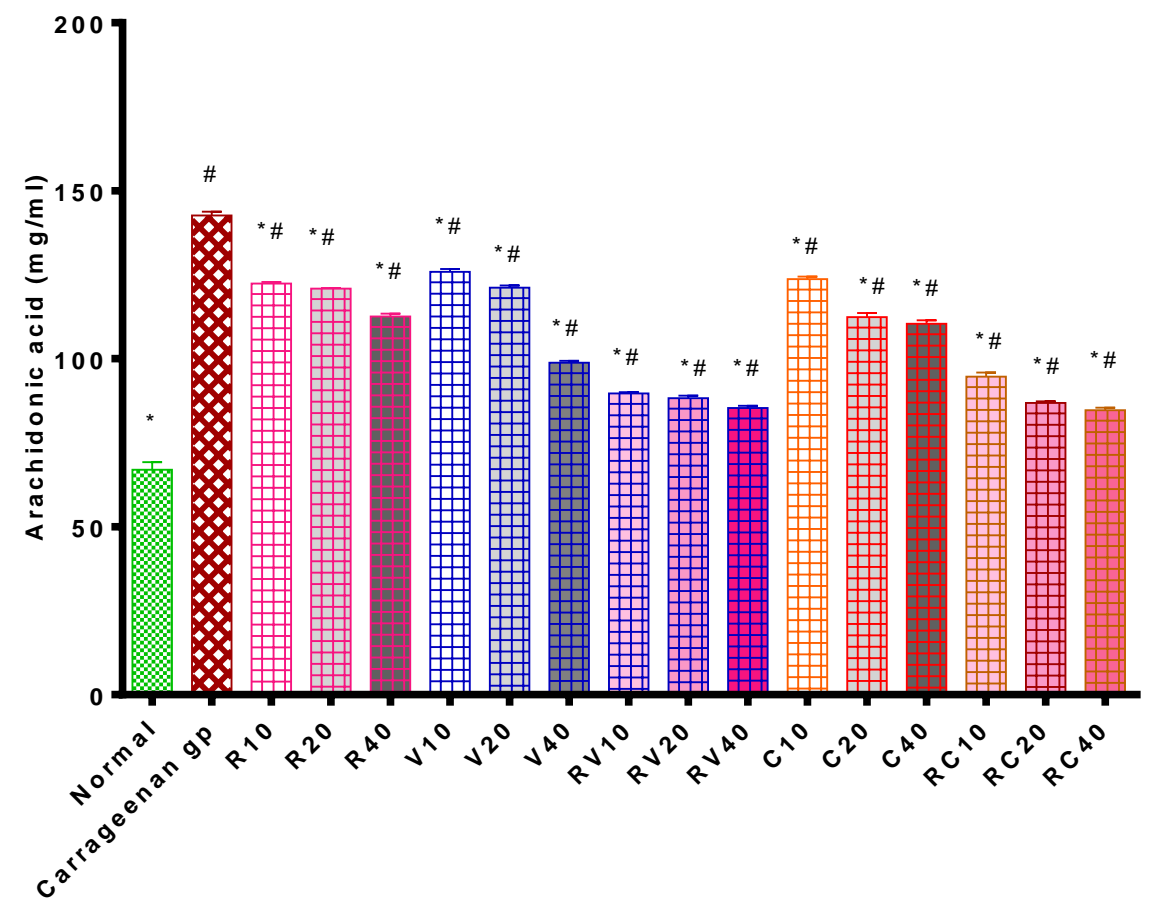

Fig. 1: Effect of adding resveratrol to diclofenac on arachidonic acid level.

"Significantly different from Carrageenan group, ${ }^{\#}$ Significantly different from normal control.

\section{Effect on arachidonic acid}

Inflammation significantly increased arachidonic acid compared to normal control $(142.6 \pm 1.2$ vs. $66.97 \pm 2.22)$. All treatments significantly lowered arachidonic acid as compared to carrageenan group where combination groups showed significant reduction in arachidonic acid levels as compared to the corresponding standalone dose levels where; levels for resveratrol combinations with diclofenac sodium $v s$. diclofenac sodium alone were $(89.68 \pm 0.39,88.31 \pm 0.7$ and $85.33 \pm 0.66$ vs. $125.9 \pm 0.83$, $121.2 \pm 0.66$ and $98.81 \pm 0.54)$ respectively and levels for resveratrol combinations with diclofenac potassium $v s$. diclofenac potassium alone were $(94.67 \pm 1.26,86.81 \pm 0.5$ and $84.68 \pm 0.76$ vs. $123.7 \pm 0.76,112.2 \pm 1.23$ and $110.4 \pm 1.04)$ respectively (Figure1).

\section{Effect on IL-1及}

Inflammation significantly increased IL-1 $\beta$ level compared to normal control $(142.6 \pm 1.2$ vs. $66.97 \pm 2.22)$. All treatments significantly lowered IL- $1 \beta$ level as compared to carrageenan group where combination groups showed comparable reduction in IL-1 $\beta$ levels as compared to the corresponding standalone dose levels (Figure 2). 


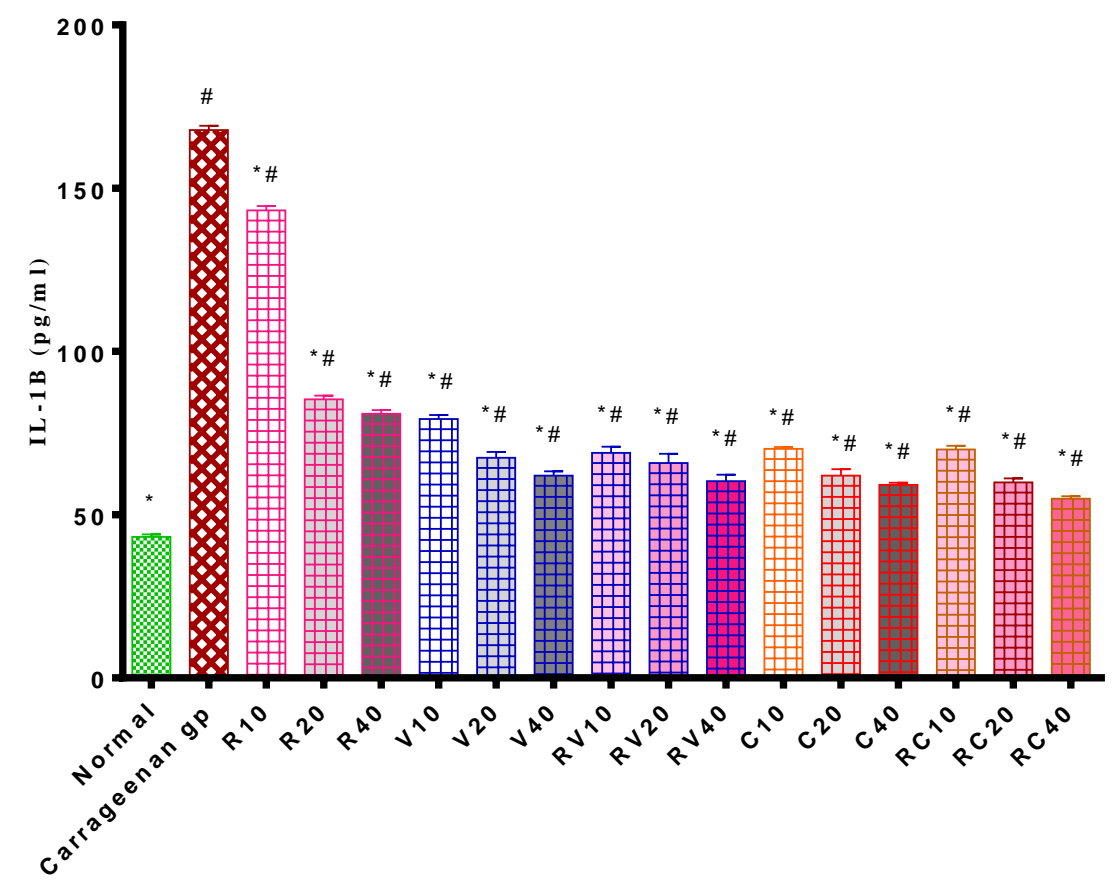

Fig. 2: Effect of adding resveratrol to diclofenac on IL-1 $\beta$ level.

${ }^{*}$ Significantly different from Carrageenan group, ${ }^{\#}$ Significantly different from normal control.

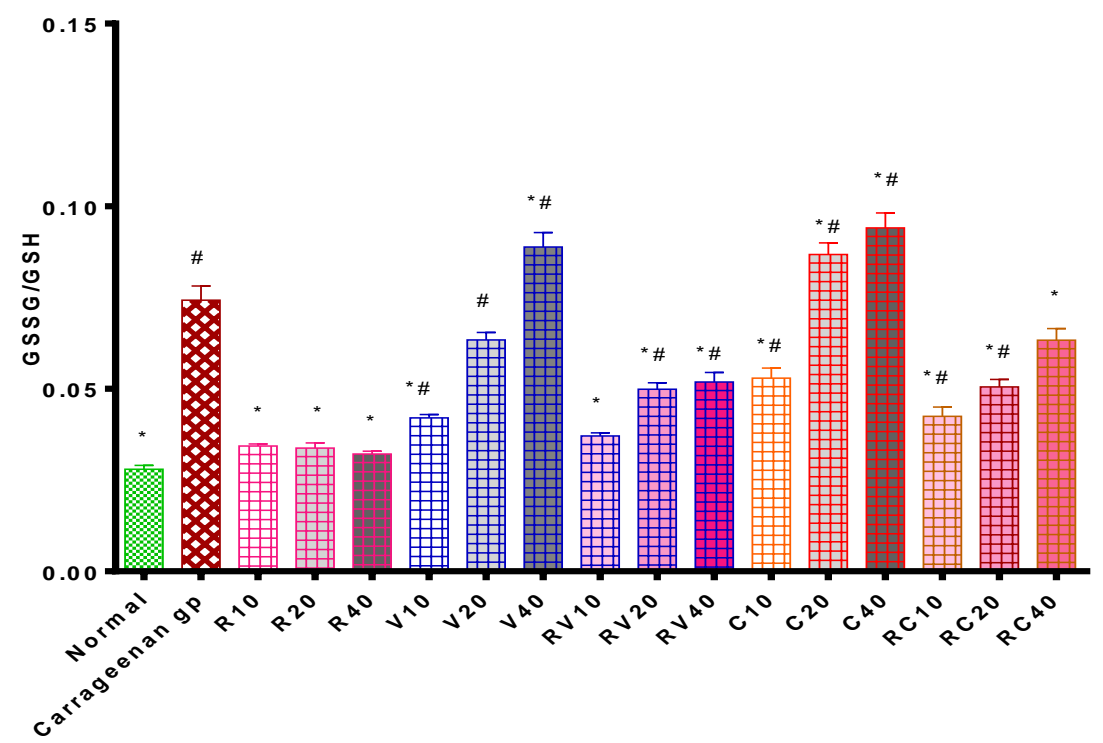

Fig. 3: Effect of adding resveratrol to diclofenac on GSSG/GSH ratio.

* Significantly different from Carrageenan group, \# Significantly different from normal control.

\section{Effect on GSSG/GSH}

Inflammation resulted in a significant increase in the conversion of reduced glutathione to the oxidized form indicating pronounced oxidative stress compared to normal control $(0.074 \pm$ 0.0039 vs. $0.028 \pm 0.001)$.

Resveratrol; at the three dose levels showed normalization in the GSSG/GSH ratio. Individual NSAIDs treatments showed noticeable dose dependent oxidative stress as seen by the elevation in the GSSG/GSH ratio. All combination treatments lowered GSSG/GSH ratio as compared to their corresponding individual NSAID treatment (Figure 3).

\section{$\mathrm{NO}_{\mathrm{x}}$ and MDA}

Inflammation resulted in a significant increase in NOx and MDA levels indicating marked nitrosative stress and oxidative stress (21.24 \pm 0.81 vs. $12.17 \pm 0.28)$ and $(344.4 \pm 9.76$ vs. $202.8 \pm$ 4.94) respectively as compared to normal control. Resveratrol; at the three dose levels showed normalization in the NOx and MDA levels. Individual NSAIDs treatments showed prominent dose dependent nitrosative stress and oxidative stress as seen by the elevation in the NOx and MDA levels. All combination treatments lowered NOx and MDA levels as compared to their corresponding individual NSAID treatment (Figures 4, 5). 


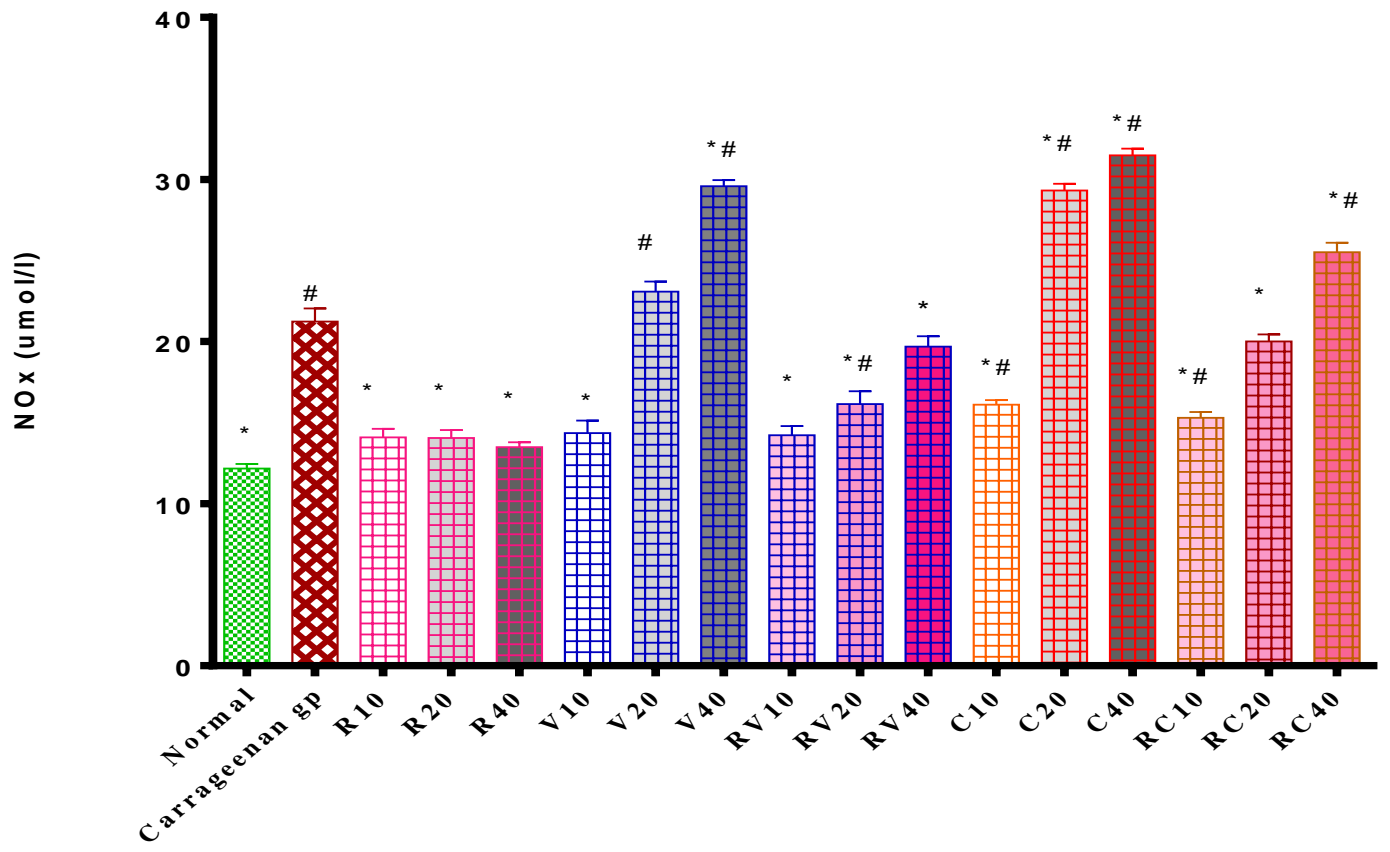

Fig. 4: Effect of adding resveratrol to diclofenac on $\mathrm{NO}_{\mathrm{x}}$ level.

${ }^{*}$ Significantly different from Carrageenan group, ${ }^{\#}$ Significantly different from normal control.

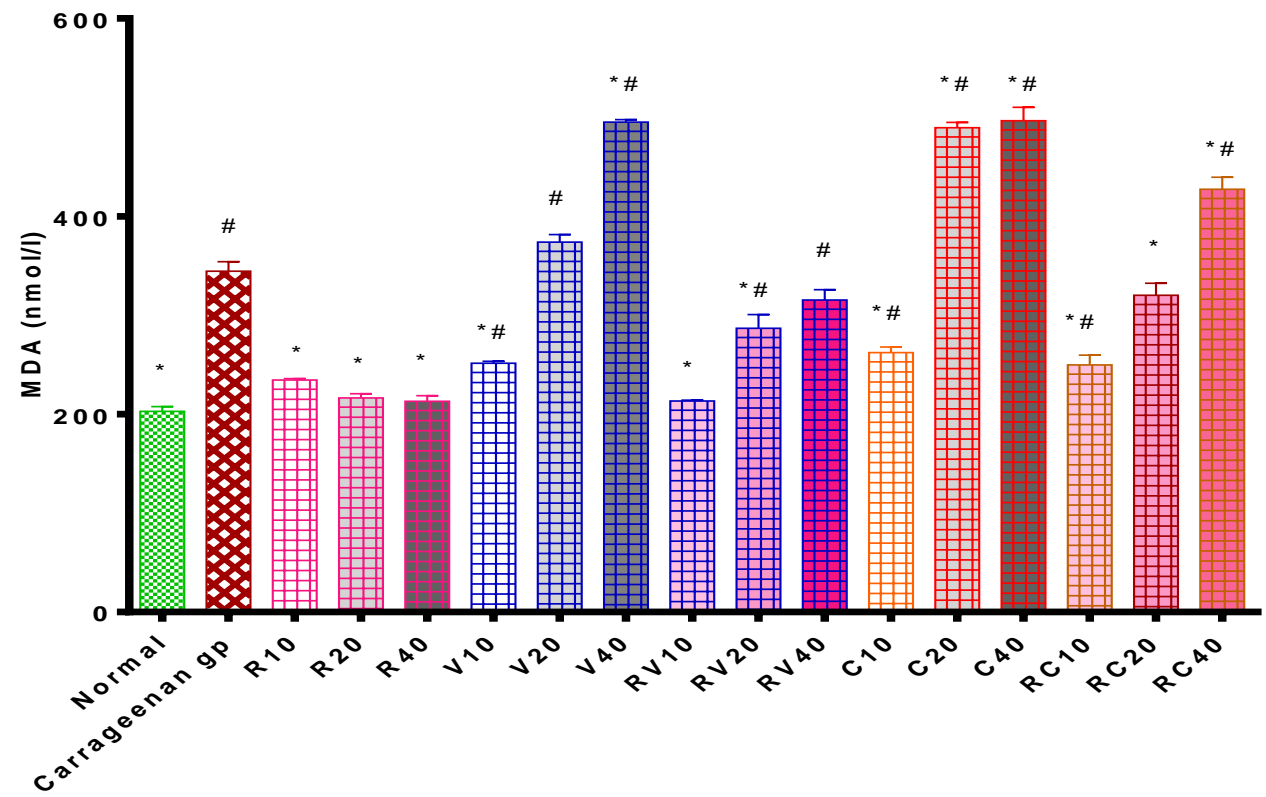

Fig. 5: Effect of adding resveratrol to diclofenac on MDA level.

* Significantly different from Carrageenan group, \# Significantly different from normal control.

\section{Effect on ALT and AST}

Inflammation resulted in significant increase in liver functions levels as compared to normal control. Standalone NSAIDs treatments showed dose dependent elevation in the ALT and AST levels as compared to normal control and even the carrageenan group at the high dose levels. Combination groups showed lower levels in both ALT and AST levels as compared to their corresponding standalone treatments indicating hepatoprotective effect (Table 2). 
Table 2: Effect of adding resveratrol to diclofenac on ALT and AST.

\begin{tabular}{lcc}
\hline Groups & ALT (unit/l) & AST (unit/l) \\
\hline Normal & $47.66 \pm 0.63^{*}$ & $106.5 \pm 1.21^{*}$ \\
Carrageenan & $56.43 \pm 0.38^{\#}$ & $123.7 \pm 1.74^{\#}$ \\
R10 & $50.89 \pm 0.38^{*}$ & $118.3 \pm 2.63^{\#}$ \\
R20 & $50.85 \pm 0.66^{*}$ & $112.1 \pm 1.39^{*}$ \\
R40 & $49.95 \pm 0.43^{*}$ & $107.3 \pm 1.62^{*}$ \\
V10 & $52.36 \pm 0.42^{* \#}$ & $121.7 \pm 0.72^{\#}$ \\
V20 & $53.98 \pm 0.58^{\#}$ & $127.8 \pm 1.10^{\#}$ \\
V40 & $59.11 \pm 0.43^{\#}$ & $138.1 \pm 1.12^{* \#}$ \\
RV10 & $51.51 \pm 0.62^{* \#}$ & $120.6 \pm 0.76^{\#}$ \\
RV20 & $51.9 \pm 0.65^{* \#}$ & $124.3 \pm 0.77^{\#}$ \\
RV40 & $52.34 \pm 0.32^{* \#}$ & $125.2 \pm 1.24^{\# \#}$ \\
C10 & $50.9 \pm 0.90^{* *}$ & $121.6 \pm 0.60^{\#}$ \\
C20 & $52.16 \pm 1.39^{* \#}$ & $134.0 \pm 2.24^{* \#}$ \\
C40 & $59.45 \pm 0.88^{\#}$ & $146.4 \pm 1.13^{* \#}$ \\
RC10 & $50.23 \pm 0.41^{*}$ & $119.4 \pm 1.29^{\#}$ \\
RC20 & $51.59 \pm 0.72^{* \#}$ & $125.1 \pm 1.89^{\#}$ \\
RC40 & $54.94 \pm 0.88^{\#}$ & $125.9 \pm 1.13^{\#}$ \\
\hline
\end{tabular}

*Significantly different from Carrageenan group, \# Significantly different from normal control.

\section{DISCUSSION}

Models of inflammation to decipher whether druginduced hepatotoxicity is augmented during episodes of inflammation may serve as useful models to predict idiosyncratic adverse drug reactions(Vickers et al., 2009).

In the present study, carrageenan was injected into the sub planter region of the right hind paw of animals to induce acute inflammation. Carrageenan injection resulted in severe paw edema, prominent increase in both arachidonic acid and interleukin-1 $\beta$ levels as well as pronounced oxidative stress and elevation in AST and ALT levels.

The inflammation is the result of interleukins secretion. Interleukins mobilize leukocytes by making them migrate from blood circulation towards the place of inflammation. These interleukins bind to their receptors at the membrane of monocytes to activate them to macrophages in order to eliminate pathogens or damaged cells and tissues. The synthesis of pro-inflammatory lipid mediators from arachidonic acid can occur via several pathways, including the prostaglandin $\mathrm{H}$ synthase (PHS) pathway, the cyclooxygenase (COX) pathway, and the lipoxygenase (LOX) pathway. Most anti-inflammatory drugs target the production of inflammatory mediators from arachidonic metabolism through cyclooxygenases 1 and 2 (COX-1 and -2), which are involved in the synthesis of pro-inflammatory leukotrienes and prostaglandin E2 (PGE2) (Lancon et al., 2016).One possibility to reduce inflammation is to inhibit the production of interleukins. NSAIDs inhibit cyclooxygenase (COX) isoforms, COX-1 and COX-2, which play a key role in the conversion of arachidonic acid to eicosanoids (Peng et al., 2016).

Results of our research revealed that; both forms of diclofenac salts and in the three dose levels (10, 20 and 40 $\mathrm{mg} / \mathrm{kg}$ )dose dependently reversed carrageenan induced paw edema and significantly reduced the levels of the inflammatory biomarkers but on the other hand; elevated the liver enzymes, nitrosative and oxidative stress biomarkers levels in a grave way. Diclofenac possesses a weak acid group (carboxyl) which non- selectively inhibits COX enzymes at the arachidonate-binding site; which accounts for its anti-inflammatory effect. In the meantime; diclofenac use has been associated with hepatotoxicity, which is linked with the formation of reactive metabolites and the lipid nature of the carboxyl group. Mild liver dysfunction is reported in $15 \%$ of patients, marked by increases of the transaminases alanine aminotransferase (ALT) and aspartate aminotransferase (AST). In $\sim 4 \%$ of patients the blood transaminase levels are $\geq 3 \times$ the upper limit of normal (ULN), and in $1 \%$ of patients the levels are $\geq 8 \times$ ULN. In rare instances, patients have been presented with severe hepatocellular necrosis and inflammation and hematological toxicity(Vickers et al., 2009).

Meanwhile; resveratrol groups $(10,20$ and 40 $\mathrm{mg} / \mathrm{kg}$ )resulted in anti-inflammatory effect that was comparable to that of the standalone diclofenac groups and moreover; showed hepato-protective effect as seen by the reduction in both ALT and AST levels.

These findings are in agreement with previous investigations as the anti-oxidant, anti-inflammatory as well as the hepato-protective properties of resveratrol either alone or in combination with other natural products has previously been reported(Csaki et al., 2009, Lee et al., 2015, Liu et al., 2015, Pan et al., 2016). Moreover, it has been recently shown that resveratrol inhibits the expression of pro-inflammatory genes in human monocytes by stimulating the synthesis of anti-inflammatory micro RNAs (Tili et al., 2010a, Tili et al., 2010b).Besides; Resveratrol was proved to be a potent inhibitor of $\mathrm{NO}_{\mathrm{x}}$ and cytokine release(Steiner et al., 2016). Finally; resveratroldiclofenac combination groups and at all dose levels showed superior effects as compared to the standalone groups, which proves our hypothesis that combining resveratrol with diclofenac would be beneficial not only through augmenting diclofenac's anti-inflammatory effect but also by hindering the possibility of idiosyncratic DILI.In conclusion we would recommend the use of the middle dose combination (Diclofenac $20 \mathrm{mg} / \mathrm{kg}+$ Resveratrol $20 \mathrm{mg} / \mathrm{kg}$ ) for patients suffering from liver injuries and in need of taking an anti-inflammatory as the overall results obtained from this combination were the most favorable.

\section{Financial support and sponsorship: Nil.}

Conflict of Interests: There are no conflicts of interest.

\section{REFERENCES}

Ahmed RF, Abdel-Rahman RF, Farid O, El-Marasy S, Hessin A. Combined hepatoprotective and antidepressant effects of resveratrol in an acute model of depression. Bull Fac Pharm Cairo Univ, 2014; 52: 19197.

Boelsterli UA. Diclofenac-induced liver injury: a paradigm of idiosyncratic drug toxicity. Toxicol Appl Pharmacol, 2003; 192: 307-22.

Boelsterli UA, Lim PL. Mitochondrial abnormalities--a link to idiosyncratic drug hepatotoxicity? Toxicol Appl Pharmacol, 2007; 220: 92-107.

Csaki C, Mobasheri A, Shakibaei M. Synergistic chondroprotective effects of curcumin and resveratrol in human articular 
chondrocytes: inhibition of IL-1beta-induced NF-kappa B-mediated inflammation and apoptosis. Arthritis Res Ther, 2009; 11: R165.

Droge W. Free radicals in the physiological control of cell function. Physiol Rev, 2002; 82: 47-95.

Farghali H, Kutinova Canova N, Lekic N. Resveratrol and related compounds as antioxidants with an allosteric mechanism of action in epigenetic drug targets. Physiol Res, 2013; 62: 1-13.

Iruzubieta P, Arias-Loste MT, Barbier-Torres L, MartinezChantar ML, Crespo J. The Need for Biomarkers in Diagnosis and Prognosis of Drug-Induced Liver Disease: Does Metabolomics Have Any Role? Biomed Res Int, 2015; 2015: 386186.

Jayatilleke E, Shaw S. A high-performance liquid chromatographic assay for reduced and oxidized glutathione in biological samples. Anal Biochem, 1993; 214: 452-7.

Karatas F, Karatepe M, Baysar A. Determination of free malondialdehyde in human serum by high-performance liquid chromatography. Anal Biochem, 2002; 311: 76-9.

Lancon A, Frazzi R, Latruffe N. Anti-Oxidant, AntiInflammatory and Anti-Angiogenic Properties of Resveratrol in Ocular Diseases. Molecules, 2016; 21.

Lee JA, Ha SK, Cho E, Choi I. Resveratrol as a Bioenhancer to Improve Anti-Inflammatory Activities of Apigenin. Nutrients, 2015; 7: 9650-61.

Liu FC, Tsai YF, Tsai HI, Yu HP. Anti-Inflammatory and Organ-Protective Effects of Resveratrol in Trauma-Hemorrhagic Injury. Mediators Inflamm, 2015; 2015: 643763.

McMillian M, Nie AY, Parker JB, Leone A, Bryant S, Kemmerer M, Herlich J, Liu Y, Yieh L, Bittner A, Liu X, Wan J, Johnson $\mathrm{MD}$. A gene expression signature for oxidant stress/reactive metabolites in rat liver. Biochem Pharmacol, 2004; 68: 2249-61.

Pan W, Yu H, Huang S, Zhu P. Resveratrol Protects against TNF-alpha-Induced Injury in Human Umbilical Endothelial Cells through Promoting Sirtuin-1-Induced Repression of NF-KB and p38 MAPK. PLoS One, 2016; 11: e0147034.

Papadoyannis LN, Samanidou VF, Nitsos ChC. Simultaneous determination of nitrite and nitrate in drinking water and human serum by high performance anion-exchange chromatography and UV detection. J Liq Chrom Rel Technol; 1999; 22: 2023-41

Peng W, Ma YY, Zhang K, Zhou AY, Zhang Y, Wang H, Du Z, Zhao DG. Synthesis and Biological Evaluation of Novel ResveratrolNSAID Derivatives as Anti-inflammatory Agents. Chem Pharm Bull (Tokyo), 2016; 64: 609-15.

Powell RD, Swet JH, Kennedy KL, Huynh TT, McKillop IH, Evans SL. Resveratrol attenuates hypoxic injury in a primary hepatocyte model of hemorrhagic shock and resuscitation. J Trauma Acute Care Surg, 2014; 76: 409-17.

Ramm S, Mally A. Role of drug-independent stress factors in liver injury associated with diclofenac intake. Toxicology,2013;312:83-96.
Reitman S, Frankel S. A colorimetric method for the determination of serum glutamic oxalacetic and glutamic pyruvic transaminases. Am J Clin Pathol, 1957; 28: 56-63.

Ren J, Mozurkewich EL, Sen A, Vahratian AM, Ferreri TG, Morse AN, Djuric Z. Total Serum Fatty Acid Analysis by GC-MS: Assay Validation and Serum Sample Stability. Curr Pharm Anal, 2013; 9: 33139.

Rubiolo JA, Vega FV. Resveratrol protects primary rat hepatocytes against necrosis induced by reactive oxygen species. Biomed Pharmacother, 2008; 62: 606-12.

Sakamoto K, Arakawa H, Mita S, Ishiko T, Ikei S, Egami H, Hisano S, Ogawa M. Elevation of circulating interleukin 6 after surgery: factors influencing the serum level. Cytokine, 1994; 6: 181-6.

Steiner N, Balez R, Karunaweera N, Lind JM, Munch G, Ooi L. Neuroprotection of Neuro2a cells and the cytokine suppressive and antiinflammatory mode of action of resveratrol in activated RAW264.7 macrophages and C8-B4 microglia. Neurochem Int, 2016; 95: 46-54.

Tili E, Michaille JJ, Adair B, Alder H, Limagne E, Taccioli C, Ferracin M, Delmas D, Latruffe N, Croce CM. Resveratrol decreases the levels of miR-155 by upregulating miR-663, a microRNA targeting JunB and JunD. Carcinogenesis, 2010a; 31: 1561-6.

Tili E, Michaille JJ, Alder H, Volinia S, Delmas D, Latruffe N, Croce CM. Resveratrol modulates the levels of microRNAs targeting genes encoding tumor-suppressors and effectors of TGFbeta signaling pathway in SW480 cells. Biochem Pharmacol, 2010b; 80: 2057-65.

Timmers S, Auwerx J, Schrauwen P. The journey of resveratrol from yeast to human. Aging (Albany NY), 2012; 4: 146-58.

Vickers DM, Zhang Q, Osgood ND. Immunobiological outcomes of repeated chlamydial infection from two models of within-host population dynamics. PLoS One, 2009; 4: e6886.

Winter CA, Risley EA, Nuss GW. Carrageenin-induced edema in hind paw of the rat as an assay for antiiflammatory drugs. Proc Soc Exp Biol Med, 1962; 111: 544-7.

\section{How to cite this article:}

Radwan OK, Ahmed RF. Amendment effect of resveratrol on diclofenac idiosyncratic toxicity: Augmentation of the antiinflammatory effect by assessment of Arachidonic acid and IL-1 $\beta$ levels. J App Pharm Sci, 2016; 6 (12): 170-177. 